\title{
A study to assess the factors associated with severity of road traffic injuries in the emergency medicine department in rural India
}

Jeedhu Radha

\author{
From EMCON 2014: International Conference on Emergency Medicine; 16th Annual Conference by the \\ Society for Emergency Medicine in India (SEMI) \\ Mumbai, India. 6-9 November 2014
}

\section{Objective}

To assess the factors associated with severity of road traffic injuries in a rural setting and to compare between the factors and the severity of road traffic injuries.

\section{Method}

Data was collected for patients coming to the emergency department of PESIMSR, Kuppam with the history of road traffic accidents. The study was a descriptive study with prospectve sampling durng the period from October 2012 to April 2014. Data were collected as per the Performadate and time of accident, date and time of arrival to emergency department, age, sex, education, place of accident, type of vehicle involved, victim involved, usage of seat belts or helmets, type of road, animal barricade, driving licence, alcohol influence and Injury Severity Score.

\section{Results}

During the study period, 750 patients were enrolled. The findings of the study showed that male patients contributed to $83 \%$ of the accidents while females were $17 \%$ with the mean age between 36 to 38 years for both the sexes. Majority of the patients were below primary school (59.7\%). Between the time of accident to the time of arrival to the hospital the mean was 15.52 minutes. With regard to the place of accident, rural area contributed to $85 \%$. The 2 -wheeler contributed to $42 \%$ among the type of vehicles with rider contributing to $39 \%$ under the victim category.

Usage of seat belts or helmets was almost non-existent at $0.4 \%$ Most of the roads were single roads (94.4\%). The usage of driving license contributed to only $45 \%$.
Alcohol consumption in road traffic accidents contributed to $48 \%$. Injury Severity Score showed that $43 \%$ of the population in the study was critically ill. The p-value is significant for type of road, area of accident, alcohol influence and usage of seatbelts/helmets.

\section{Conclusion}

Road traffic injury has emerged as a major public health problem which can be definitely prevented and controlled. It places an undue burden on the health care system which is struggling to cope up with prevailing disease burden of communicable diseases and other non-communicable diseases. Efforts need to be made in all areas concerned with road safety, enforcement, education and emergent care.

Published: 22 April 2015

\section{doi:10.1186/1865-1380-8-S1-01}

Cite this article as: Radha: A study to assess the factors associated with severity of road traffic injuries in the emergency medicine department in rural India. International Journal of Emergency Medicine 2015 8(Suppl 1): 01. 